\title{
Spontaneous Corneal Rupture One Week after Intrastromal Ring Segment Surgery
}

\section{Agostino Salvatore Vaiano, Giacomo De Benedetti, Rosanna Perno, Gaudioso del Monte,} Cristiana Valente, Guido Caramello

\section{ABSTRACT}

Purpose: To report a case of spontaneous (nontraumatic) rupture of the cornea 7 days after intrastromal ring segment surgery in a patient with pellucid marginal degeneration (PMD).

Methods: Case report.

Results: A 37-year-old African woman complains blurred vision, photophobia, foreign body sensation and redness in her left eye 7 days after an uneventful implantation of a Ferrara intrastromal corneal ring segment (ICRS) for PMD. Left eye examination revealed the rupture in the thinnest point of the cornea between the limbus and the implanted lower ICRS, and the iris prolapsed through the wound.

Conclusion: To the best of our knowledge, this case is the first documented spontaneous rupture of the thinnest point of the cornea in a patient with PMD treated successfully with the ICRS procedure. We examined the causes of this early and dramatic evolution and emphasize the importance of a careful follow-up.

Keywords: Anterior segment of the eye, Corneal dystrophy, Corneal stroma, Intrastromal corneal rings, Pellucid marginal degeneration.

How to cite this article: Vaiano AS, De Benedetti G, Perno R del Monte G, Valente C, Caramello G. Spontaneous Corneal Rupture One Week after Intrastromal Ring Segment Surgery. Int J Kerat Ect Cor Dis 2013;2(1):43-46.

\section{Source of support $\mathrm{Nil}$}

Conflict of interest: None declared

\section{INTRODUCTION}

Intrastromal corneal ring segments (ICRS) are currently used to treat corneal ectatic disorders, including keratoconus, pellucid marginal degeneration (PMD), and post laser in situ keratomileusis (LASIK) ectasia., ${ }^{1,2}$

Ferrara ICRS implantation by flattening the soft ectatic corneal tissue and decreasing asymmetrical astigmatism provide an important alternative for maintaining correct distance visual acuity (CDVA) and for delaying, if not avoiding, more complicated surgical procedures in PM D. ${ }^{3}$

Several postoperative complications have been described for ICRS implantation in keratoconus, but few case reports or studies of PM D treated with ICRS have been published. ${ }^{3,4}$

We report a case of spontaneous rupture at the thinnest point of the cornea after ICRS surgery. To our knowledge, spontaneous corneal rupture after the ICRS procedure has not yet been reported.

\section{CASE REPORT}

A 37-year-old A frican woman whose symptoms included blurred vision, photophobia, foreign body sensation and redness in her left eye arrived in the emergency room of the Department of Ophthalmology at Santa Croce e Carle Hospital in Cuneo. She indicated no trauma in that eye. Seven days prior to presenting, she had undergone an uneventful implantation of ICRS (Ferrara O phthalmics, B elo Horizonte, Brazil) in the left eye for PMD in the same department. B efore implantation, the uncorrected distance visual acuity (UDVA) in her left eye was 20/200, with a CDVA of 20/100 and refraction of $+3.50-6.0 \times 110$. The flattest meridian was measured to be 43.2 at 111 and $42.13 \mathrm{D}$ at 109, whereas the steepest meridian was measured to be 51.7 at 21 and $49.92 \mathrm{D}$ at 19 using 0 rbscan ${ }^{\circledR}$ (version 3.10.27, B ausch \& Lomb, Orbtek Inc, Salt Lake City, UT, USA) and video keratometry (EyeSys T echnologies Corneal A nalysis System 2000, EyeSys Instruments, Houston, TX, USA), respectively. The pupil diameter was $3.2 \mathrm{~mm}$, and the white-to-white diameter was $11.4 \mathrm{~mm}$ as measured by Orbscan. The optical pachymetry maps obtained with V isante optical coherence tomography (V isante OCT, Carl Zeiss M editec, Dublin, California, USA) and Orbscan showed the thinnest point in the inner part of the cornea to be 442 and $511 \mu \mathrm{m}$ thick respectively (Figs 1 and 2). The intraocular pressure and fundus oculi were normal in both eyes. The lid function, corneal sensation and tear function were normal.

A tanamnesis, our patient reported no trauma or previous infection in that eye or collagen vascular disease.

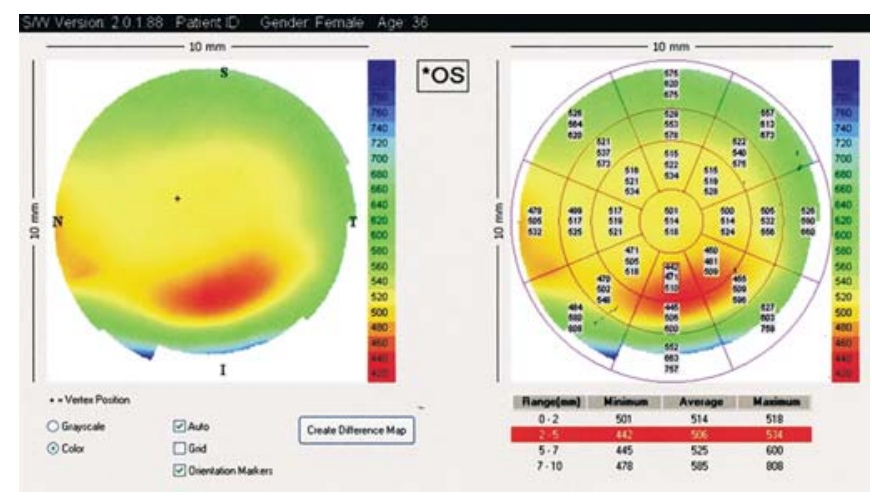

Fig. 1: Visante optical coherence tomography image: pachymetry map 


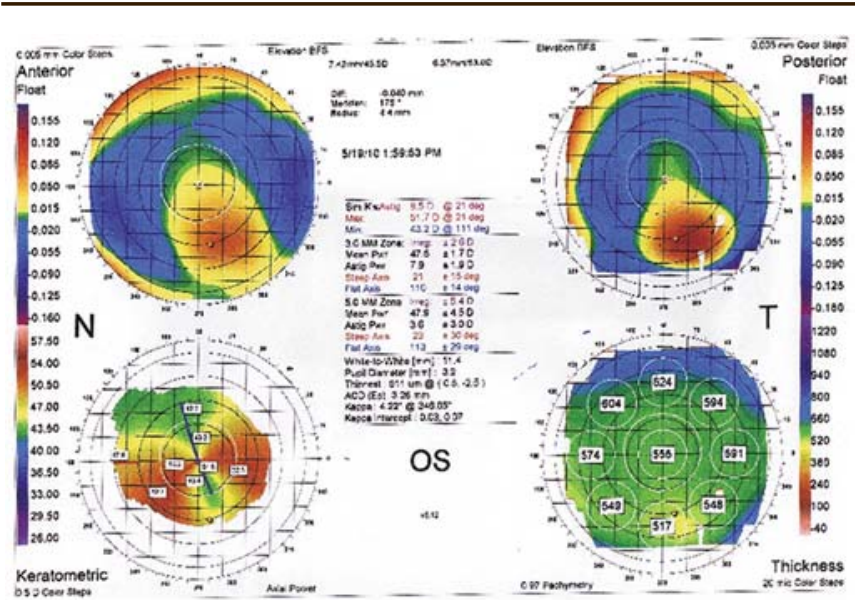

Fig. 2: Orbscan map

The ICRS surgery was performed after written informed consent was obtained from the patient and after explaining the surgery and potential complications. Standard antiseptic surgical routines were followed, including topical povidoneiodine $0.05 \%$ before surgery, sterile drapes, and the use of prophylactic antibiotic therapy with ofloxacin $0.3 \%$ (Exocin, A llergan, Ireland), taken 4 times daily for 1 week before surgery. Topical anesthesia with lidocaine $\mathrm{HCl}$ gel $2 \%$ (X ylocaine jelly, A straZeneca A B, Sweden) was used. The center of the virtual circle created by the 2 rings, which was 5 to $6 \mathrm{~mm}$ in diameter, was positioned in the corresponding center of the pupil and marked. A $n$ axial incision of $1.4 \mathrm{~mm}$ was created with a diamond blade adjusted to al most $80 \%$ of the total corneal thickness, which was $480 \mu \mathrm{m}$ as measured by US (NIDEK US-1800 ultrasonic pachymeter Echoscan, A chi, Japan) at the incision site at 20. After the incision, creation of the intrastromal corneal tunnels was performed with a $1.2 \mathrm{~mm}$ specialized blunt dissecting instrument. Following this step, the PM M A ring segments (mediphacos: upper $5 \mathrm{~mm}, 90^{\circ}, 200 \mu \mathrm{m}$ and lower $5 \mathrm{~mm}$, $160^{\circ}, 300 \mu \mathrm{m}$ ) were implanted in the created intrastromal channels without sutures and oriented in accordance with the specific nomogram. The patient received ofloxacin $0.3 \%$ and prednisolone acetate 1\% drops (Pred Forte, A llergan) 4 times daily for 1 week. Postoperatively, the patient was seen for a follow-up visit on the first day, and the UDV A had improved to $20 / 67$.

On examination in the emergency room at 7 days postsurgery, she presented with an UDVA of 20/20 in the right eye and hand movement in the left eye. The slit-lamp examination revealed that the right eye was normal, whereas the left eye had eyelid edema, hypotony, conjunctival hyperemia, and, surprisingly, a corneal melt with perforation from 4 to $8 o^{\prime}$ clock in the area of thinning between the limbus and the implanted lower ICRS with the iris prolapsed through the wound. The anterior chamber was absent, with contact between the endothelial cells and the lens (Fig. 3).

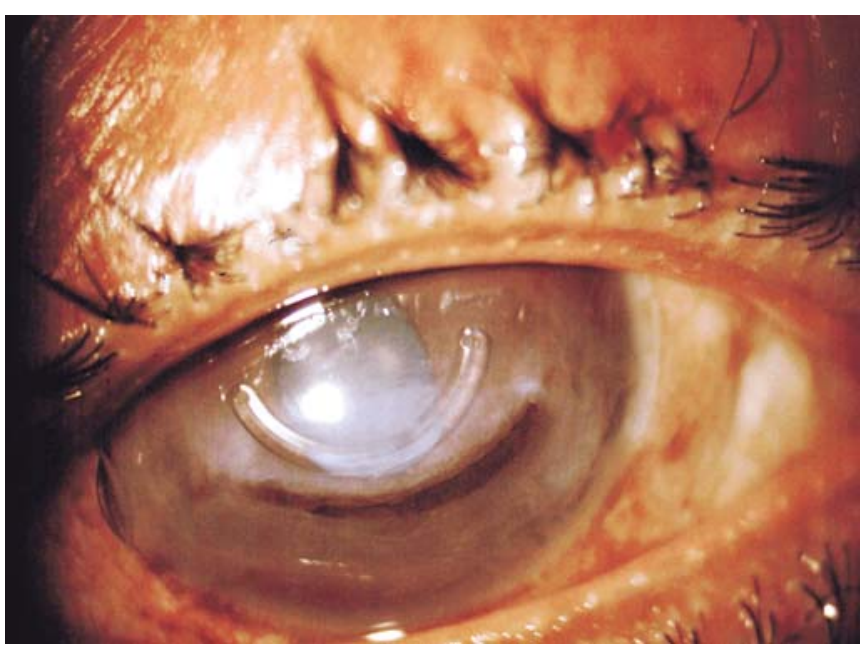

Fig. 3: Slit-lamp examination showing perforation from 4 to 8 o'clock in the area of thinning between the limbus and the lower ICRS that was in place and with prolapsed iris through the wound

We decided to suture the wound quickly to avoid infection (Fig. 4). D uring surgery, we had to remove the lower ICRS, which allowed us to reposition the iris and close the edge, though corneal melting caused great difficulty. A bandage contact lens was placed at the end of the surgery. Ofloxacin was instilled four times daily for 2 weeks. Three weeks after ICRS surgery, a large diameter penetrating keratoplasty (diameter of $9.5 \mathrm{~mm}$ ) was performed (Fig. 5). The patient was followed for 14 months, and she has followed an uncomplicated course.

\section{DISCUSSION}

To date, this is the first case of spontaneous rupture of the cornea after ICRS surgery. Because the specific ocular history of the patient ruled out traumatic events we supposed that the rupture was due to extreme thinning and melting of the cornea over and below inferior ICRS.

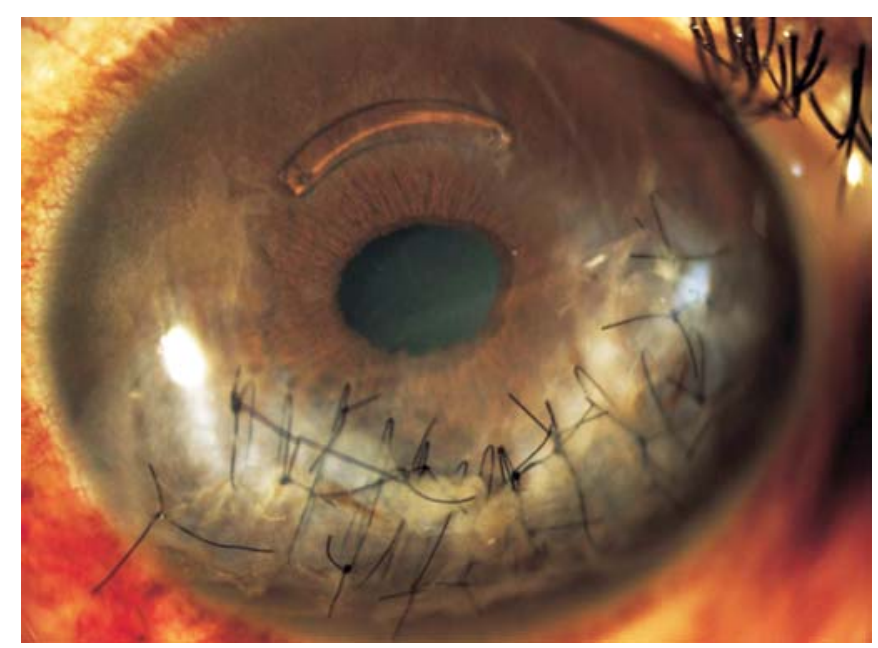

Fig. 4: Slit-lamp examination the day after the suture of the corneal melting wound 


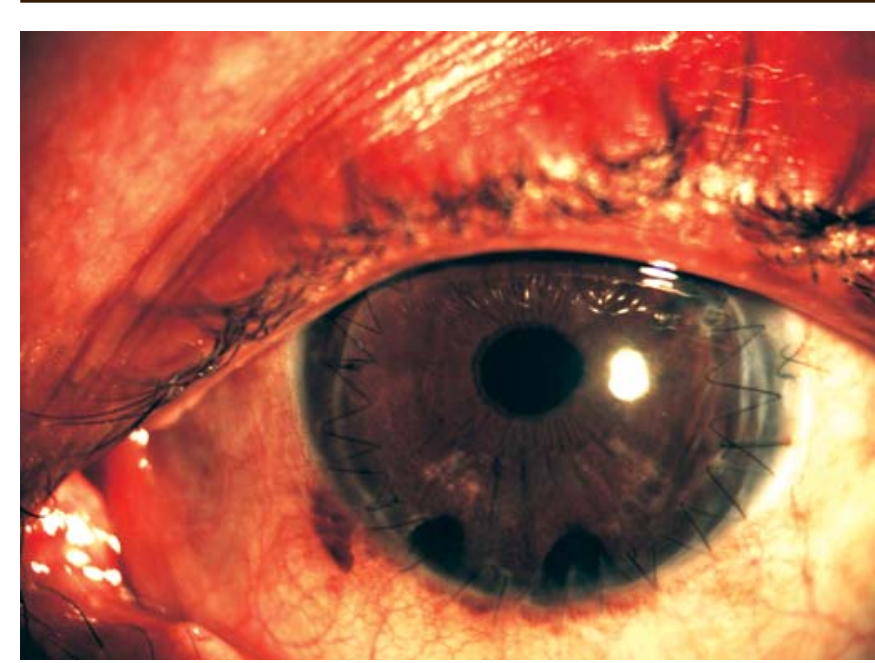

Fig. 5: Slit-lamp examination after large diameter penetrating keratoplasty

A fter corneal surgery, melting can be associated with infectious, inflammatory or trophic causes. The pathogenesis is not completely understood, although epithelial defects are always present, and stromal production of proteases might be involved. A cornea denuded of epithelium resists collagenolysis poorly because immune mediators and collagenase enzymes attack the exposed stroma, and inflammatory cells further compound the progression of ulcerative melting. E pithelial problems after surgery include defects secondary to cell loss during or after surgery, epithelial irregularity and superficial punctate keratopathy.

Intrastromal corneal ring surgery increases the risk of melting as a result of ring segment movement with exposure through the wound and corneal thinning over the ring segments. $^{5}$

Furthermore, we can improve the results and reduce the complications of ICRS surgery by modifying the procedure or combining it with others types of surgeries.

The traditional mechanical technique for tunnel creation can lead several complications: epithelial defects, anterior and posterior perforations during channel creation, extension of the incision toward the central visual axis or limbus, asymmetric placement, persistentincisional gaps, decentration, stromal thinning, and corneal stromal edema around the incision and channel from surgical manipulation. 6,7

The femtosecond laser (IntraL ase Corp.) might reduce the incidence of intraoperative and postoperative tunnel complications. ${ }^{7,8}$ B ecause of its surgical effects via photodisruption, the laser can create a predetermined depth channel size easily and quickly. This laser, less dependent on surgeon skills, allows for better manipulation of ICRS, which reduces corneal surgical trauma.

In the same way, collagen cross-linking $(C X L)$, which increases the stiffness of the cornea using ultraviolet $A$
(UVA) light and photosensitized riboflavin, could be considered for use as a supplement to ICRS surgery to prevent regression or for stabilization of the effects. ${ }^{9}$ M oreover, the results of biomechanical coupling from local collagen changes around the segments can reduce the risk of corneal melting.

This case illustrates the need for surgeons to be aware of this potential complication when using ICRS in PMD patients and to have future studies that could create a proper mathematical model for ectatic corneal considering that the implants determines the maximum amount of strain in the inferior peripheral cornea at the same point of greatest protrusion and maximum thinning.

\section{REFERENCES}

1. Rodriguez-Prats J, Galal A, Garcia-L ledo M, De La Hoz F, A lió JL. Intracorneal rings for the correction of pellucid marginal degeneration. J Cataract R efract Surg 2003;29:1421-24.

2. Kymionis GD, Tsiklis NS, Pallikaris AI, Kounis G, Diakonis VF, A styrakakis N, et al. Long-term follow-up of Intacs for post-LASIK corneal ectasia. Ophthalmology 2006;113: 1909-17.

3. Piñero DP, A lio J L . Intracorneal ring segments in ectatic corneal disease - a review. Clin Experiment Ophthalmol 2010;38: 154-67.

4. Ertan A, Colin J. Intracorneal rings for keratoconus and keratectasia. J Cataract R efract Surg 2007;33:1303-14.

5. Zare MA, Hashemi $H$, Salari MR. Intracorneal ring segment implantation for the management of keratoconus: Safety and efficacy. J Cataract Refract Surg 2007;33:1886-91.

6. Coskunseven E, K ymionis GD, Tsiklis NS, et al. One year results of intrastromal corneal ring segment implantation (KeraRing) using femtosecond laser in patients with keratoconus. Am J Ophthalmol 2008;145:775-79.

7. Ertan A, Kamburoğlu G. Intacs implantation using a femtosecond laser for management of keratoconus: Comparison of 306 cases in different stages. J cataract R efract Surg 2008;34:1521-26.

8. E rtan A, K amburoğlu G, A kgün U . Comparison of outcomes of 2 channel sizes for intrastromal ring segment implantation with a femtosecond laser in eyes with keratoconus. J Cataract R efract Surg 2007;33:648-53.

9. Kamburoglu G, Ertan A. Intacs implantation with sequential collagen cross-linking treatment in postoperative L A SIK ectasia. J Refract Surg 2008;24:S726-29.

\section{ABOUT THE AUTHORS}

\section{Agostino Salvatore Vaiano}

Consultant, Department of O phthalmology, R efractive Surgery and Cornea U nit, Santa Croce e Carle H ospital, Cuneo, Italy

\section{Giacomo De Benedetti (Corresponding Author)}

Head, Department of O phthal mology, R efractive Surgery and Cornea Unit, Hospital Quirón Donostia, Parque A Icolea, 7, 20012, San Sebastián, Spain, e-mail: gdebenedetti.ss@ quiron.es 


\section{Rosanna Perno}

Consultant, Department of O phthalmology, R efractive Surgery and Cornea U nit, Santa Croce e Carle Hospital, Cuneo, Italy

\section{Gaudioso del Monte}

Consultant, Department of O phthalmology, Refractive Surgery and Cornea U nit, Santa Croce e Carle Hospital, Cuneo, Italy

\section{Cristiana Valente}

Consultant, Department of O phthalmology, R efractive Surgery and Cornea U nit, Santa Croce e Carle H ospital, Cuneo, Italy

\section{Guido Caramello}

Head, Department of Ophthal mology, R efractive Surgery and Cornea Unit, Santa Croce e Carle H ospital, Cuneo, Italy 